\title{
High-Speed Railway Bridges Under Vehicle Moving Load And Near Fault Seismic Ground Motions - Review
}

\author{
Amudhan V 1*, Hui Qian² \\ 1 Research Scholar, Department Of Civil Engineering, Hindustan University, Chennai \& Zhengzhou \\ University, Zhengzhou, China. \\ 2 Professor, Department Of Civil Engineering, Zhengzhou University, Zhengzhou, China. \\ * Corresponding Author: amudhanresearch@gmail.com
}

Received: 10-03-2021

Accepted: 02-11-2021

\begin{abstract}
All time needs of maintenance of high speed train system and its infrastructure safety is must all over the world. Nowadays, for the smooth running of HSR trains, most of the country depend on the HSR bridge structures, but there is still a lack of understanding in the behavior of structures under various factors like seismic and high speed moving load effects. To study the dynamic behavior of HSR bridges, it is important to consider the interaction of moving vehicle - Bridge structure - Ground surface showing that the different parameters involved in understanding the response of the structure. The main motivation of this study is to initiate the better understanding of the various parameters effects by those seismic and moving vehicles over the dynamic behavior of the HSR bridges. The effects of forward directivity pulses were considered to understand the behavior of HSR bridges against near fault earthquakes, which can make substantial impact over the seismic demand capacity of the moving vehicles and structures. The effects of high speed moving vehicles over the HSR bridges to understand the parameters involved in the dynamic behavior of the coupled system. This literature review can help the beginners and who initiate the study based on the dynamic behavior of high speed railway bridges and its components under seismic and moving load effects.
\end{abstract}

Keywords: High speed train, near-fault Earthquakes, Moving load, Dynamics of railway bridges, Resonance, vibrations.

\section{Introduction}

Implementation of High Speed Rail plays a vital role in the current fastest transportation mode in all over the world due to this necessity of this transport system day by day upgrading with railway design standards occurs for safety and reliability of the system. By the same time due to the high population in China, people were in demand of rapid transport between the commercial cities, Fig.1 shows that the high-speed rail developed rapidly in China over the past 15 years with substantial funding from the Chinese government, especially the economic stimulus program during the Great Recession. In that time, the line laying process for successful running of HSR railway system were executed. And bridges were playing a major role in supporting the railway structures and movement of high-speed vehicles. Comparison with other countries like Germany, Italy, United States, Japan, Spain HSR Lines, China having the higher bridge occupation ratios giving the bridge ratio of 1.3-32.2\% (Fig.2) from various rail lines which helps to protect the agricultural and arable land economically as well as for the speedy constructions without any delay (He et al., 2017). Due to smoothness and safety running of the train most of the bridge length were stretching about more than ten to twenty kilometers which makes us to realize that most of the high speed trains will be travelling over the bridges most of the time when the earthquake occurs (Xia et al., 2006). So the excessive vibrations induced by the earthquake apart 
from the vibrations by moving vehicles which causes the discomfort for the bridge structures also it will affects the safety of the train vehicle which is passing through the structure.

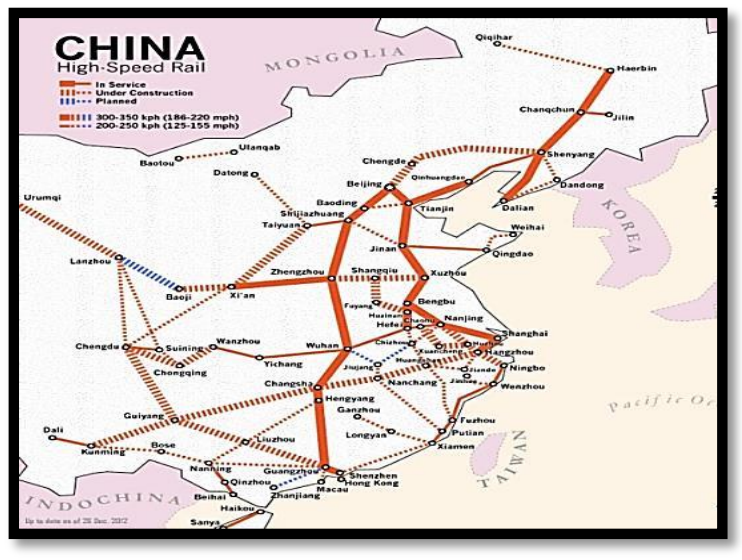

Fig. 1. China HSR Railway line map

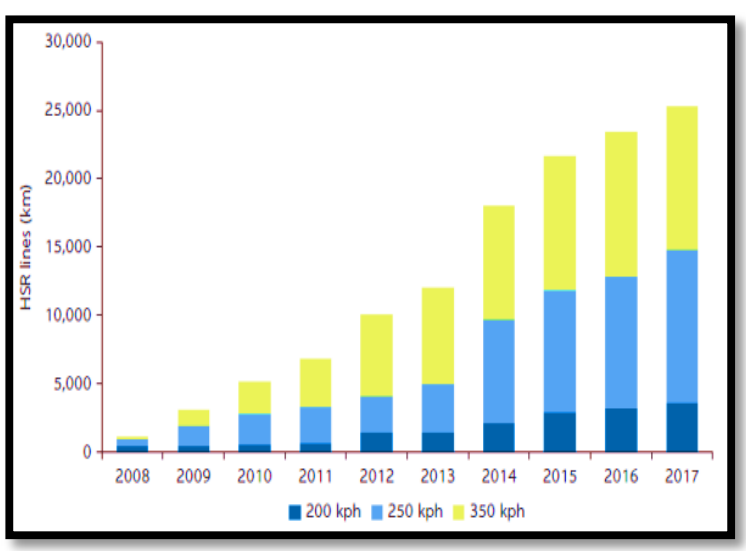

Fig. 2. Raising trends of HSR with bridges by the last 10 year plan of China.

In the last 20 years, there were more than the count of hundred bridges which were collapsed and damaged due to various reasons worldwide. In those cases, most of the scenarios show that the damage induced to the bridge structure due to seismic vibration and dynamic excitation of the vehicle movements have been raised day by day and it indicates the necessity of implementing various initiatives to study the control measures and dynamic response of the bridge structures due to the excessive vibrations which affects the smooth running of the train as well as long term performance of the structures and its components. Recent studies and various personal observations of researchers show that around 95 major earthquakes caused collapse or defects in railway bridges and it's components that count few are explained by the following information's. In the 1906 California earthquake, movement along the fault rupture caused separation between the connections of the substructure of Southern Pacific Railroad Bridge over the Pajaro River. During the 1964 Alaska earthquake due to the liquefaction issues the bridge structure experienced the vertical and lateral buckling of timber trestles and the lateral movement of column-trestle connections (William and Byers, 2004). In the 1995 Kobe earthquake caused a severe damage to the bridges because of collapse in concrete rigid frame viaducts due to inadequate ductile detailing to withstand the Seismic Loads and also by the bearing and restrainers failure (Comartin et al. 1995). One of the common complaints arising frequently is the seating failure of the girder at the interconnection joints which cause the adjacent girders move out of phase. (Roberts et al 2005) And the intensive statement says that the major failure due to the unseating problem caused by insufficient support width at the connections. (M. Saiid Saiidi, et al. 2005) Bearing in mind the major earthquakes with high 
intensity (Chi-Chi, Kobe, and Northridge earthquakes) shows that the lack of consideration for seismic vibrational control for the acting lateral loads without causing damage to the bridge. High intensity earthquake result in the longitudinal displacement which causes excessive displacement and opening at the intermediate connections in multi-span continuous bridges.

Wenzhou train collision (Fig.3) was the major HSR train collision in China where two trains derailed each other, and four cars fell off the viaduct. 40 people were killed, at least 192 were injured, 12 of which were severe injuries. The collision was the first disastrous smash involving high-speed rail (HSR) in China, and is the third deadliest HSR accident in history. As mentioned above, there was a high intensity Niigata earthquake on 2004, one of the High-speed train derailed when running on the elevated bridge at $200 \mathrm{~km} / \mathrm{hr}$., which breaks the safety record and creates loads of controversy about Japan Shinkansen railway system. A brief 12-15 seconds, massive earthquake of 8.9 magnitude hit mainland Japan on 2011, which causes displacement of tracks in 2,590 places and the railway supporting structural components damaged. And on the same day, one of the trains running under test without passengers were derailed and halted by the emergency braking. Rails where speed or not, but it's one of the safest transport to go around because as per the National Safety Council review of 10 years of transportation fatalities between 1990 and 2011- the Bureau of Transportation Statistics shows that nearly 900,000 people died in highway crashes, while fewer than 15,000 died in train collisions. Based on the statistic, the real fact of safety is really with rails even though the collapse and unexpected damages happened because of the natural calamities. Therefore the researchers are keen to take initiatives in all kinds of measures to control the vibrations induced by earthquakes and the excessive vibrations induced by the moving vehicles towards the structure. In this review work, we start by reviewing articles which relate to the dynamic response of bridges under earthquake loads and moving loads of train.

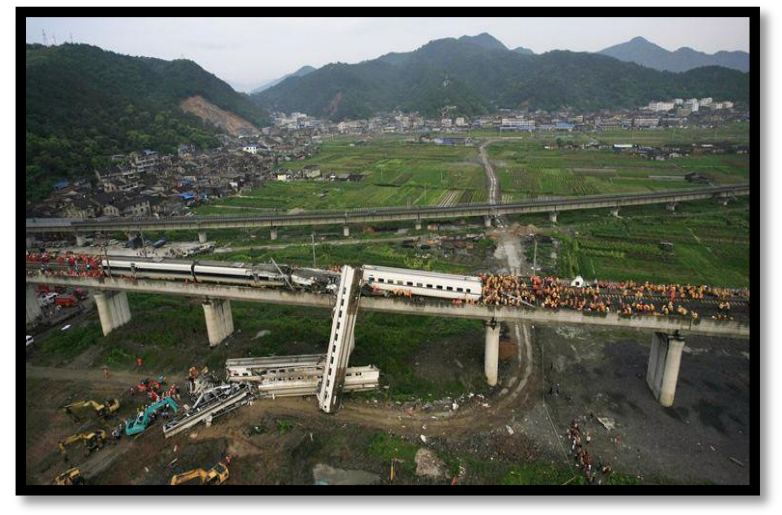

Fig. 3. Wenzhou train collision. China, 2011

\section{Seismic effects in high speed railway bridges}

Meanwhile we entered 21st century, in and around 800 earthquakes with the magnitude more than 6.0 have happened in China because it is situated between the two largest seismic belts the circum-Pacific seismic belt and the circum-Indian seismic belt. And the regions cuddled by the Pacific plate, the Indian plate, and the Philippine plate, the seismic fracture zones are well developed in this area. Earthquakes have occurred in almost all the provinces, municipalities and autonomous regions except these three regions named Guizhou, Zhejiang and Hong Kong which shows the necessity of seismic design consideration for all kind of structures. On October, 2004, an earthquake disaster happened with a magnitude of 6.8, which caused a derailment incident of Shinkansen train (fig.4. (a)) carrying about 155 passengers with $200 \mathrm{~km} / \mathrm{hr}$. from Tokyo to Nilgata station over Japan is a serious case to be recalled. Additionally in the following year, another incident occurred in Taiwan, where the derailment of high-speed rail carriage during the maximum intensity of 6.4(fig.4. (b)). In that case, the high cost project like high-speed 
railway structural system needs special attention to reduce the damage induced by earthquakes. The railroad industry is vitally interested in maintaining reliability in its infrastructure to assure safety for its employees, passengers, customers' goods and the public at large (AREMA, 2018).

(a)

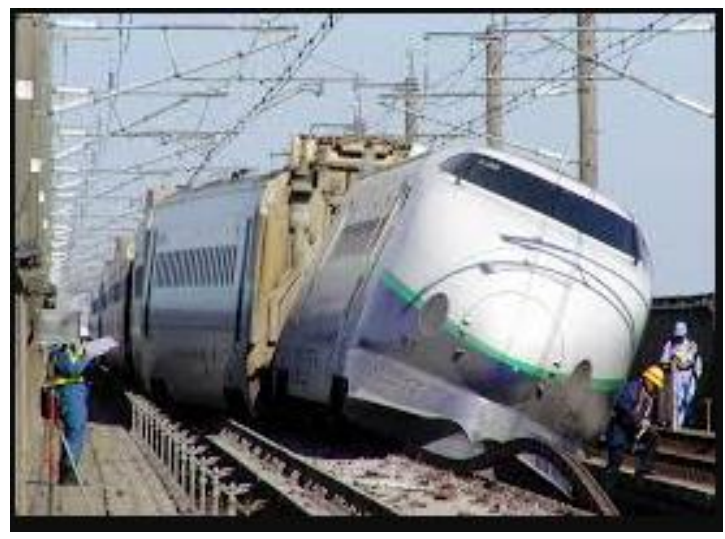

(b)

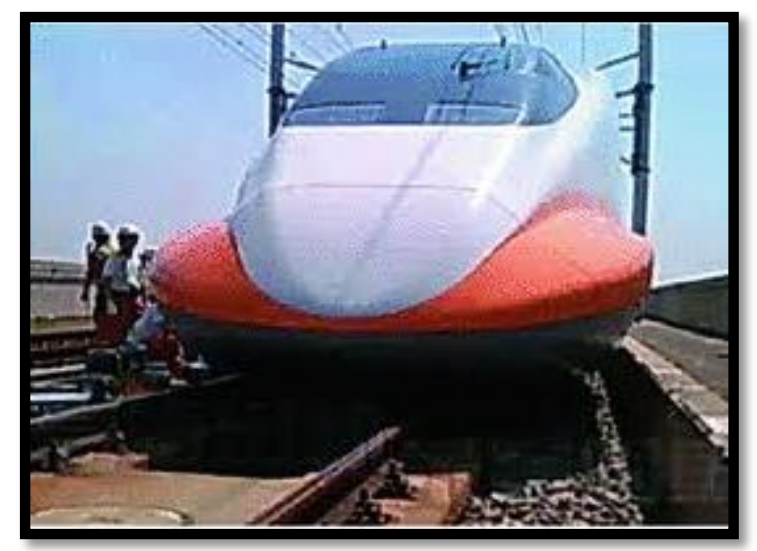

Fig. 4. Seismic effects on High Speed Railway \& its structures (a) Derailment of high-speed trains on bridges due to Niigata Chuetsu earthquake (b) ) Derailment of high-speed trains on bridges due to Taiwan earthquake

\subsection{Earthquakes in China}

Earthquakes in China happens because of major 23 seismic belts as shown in fig.5 over the five regions whereas Taiwan province, South-West areas (Tibet, West part of Sichuan province and the mid-West of Yunnan province), North-western area (Gansu province, Hexi Corridor, Qinghai, Ningxia and Tian Mountain areas), Northern part (Taihang Mountain, river beds of Fen river and Wei river, Yin Mountain-Yan Mountain area, mid in Shandong and Bohai Bay) and at last the South-eastern coastal areas, such as Guangdong, Fujian (Xiao, 2015). And these earthquakes were classified base $d$ on the intensity of the waves, highest frequencies, epicenter and the faults wide distribution. According to the above statements, the high speed railway system in China is mostly covers all over the regions where the sites are surrounded by several known major seismic zones. Moreover, it becomes a major natural disaster intimidation for the infrastructure and people's safety in peaceful time (Xiao, 2015).

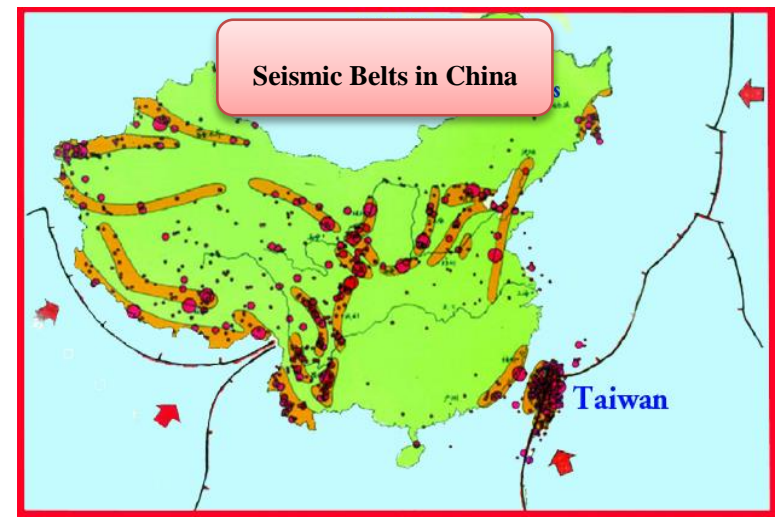

Fig. 5. Schematic distribution of Strong Earthquakes and Seismic Belts in China

\subsection{Earthquake motions based on the faults}

The high speed rail are mostly pass through all over the major cities in China where the sites are surrounded by different faults, which provides possibilities for trains to experience the effects of different seismic motions. Therefore that motions induced by the seismic excitations differ from place to place due to the different propagation path and different earthquake faults. Those 
ground motions replicates with different intensities levels including different peak ground accelerations (PGA), durations and characteristic periods and different local site conditions which going to act on the high-speed railway bridges (Wei et al., 2018; Davoodi et al., 2012). And they were classified based on the distance and magnitude of the shaking such as near fault earthquake which having the large velocity pulse as compared to the far fault earthquake as show in fig.6 (Akkar et al., 2005). Those pulses will be governed by the distance of the station, location of the rupture fault, direction of the slip on the fault and also the direction of the fault rupture towards the recoding station which termed as "Forward directivity effect" and it is generated by the vertical strike slip and dip slip faults (Chopra and Chintanapakdee, 2001; Adanur et al., 2012; Beiraghi et al., 2016).

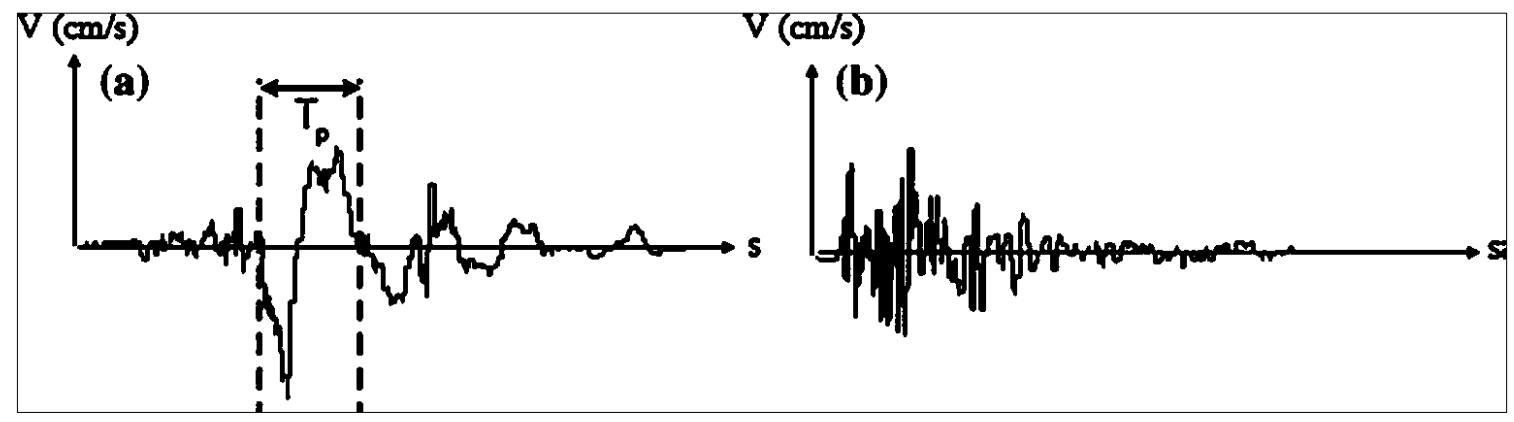

Fig. 6. Velocity time histories of strong ground motion of a) Near-fault strong ground motion b) Far-fault strong ground motion.

\subsection{Characteristics of near fault ground motions}

Previous researches conducted numerous comparisons between the near faults and far fault motions to study the structural response of the structures and to understand the characteristics of near fault pulse-like motions. Those motions will induce the impulsive velocity effect from the rupture directivity effect and take place normal vertical to the fault plane and it can be witnessed by the velocity time histories of countless strong earthquakes (Wu et al., 2016). And the important feature should be observed is formation of step like displacement records which named as fling effect which is induced by the permanent tectonic offset of the rupture fault where the displacement profile and the intensity of the aftershocks were developed asymmetrically with maxima at the opposite end of the fault to the earthquake focus (Wu et al., 2016; Kim and Sanderson, 2008). The investigation carried out through SDOF systems with and without fling effect by using MATLAB model showed that the seismic demand increased also the structural response depends on the ratio of fling pulse to the fundamental period of the structure (Jamnani et al., 2013). At last the unique feature of the NF ground motions is the hanging-wall effect which can induce the $46-60 \%$ of higher PGA values in the range of 5 to 25 kms, it's mainly due to the proximity of the fault plane to hanging wall sites where the sites on the hanging wall of dipping fault closer to the fault as a whole causes than do sites at the same closest distance on the footwall causes formation of shortest ground motion (Tao and Wang, 2003). Recently response spectrum characteristics of the near fault ground motions also studied and it has been proved that the ratio of the PGV/ PGA can be a major parameter to recognize the $\mathrm{NF}$ earthquake effect with structural response, when the PGV/PGA values are higher indicates ground acceleration response spectrum area width will be further wider which is always interrelated to the structural response (Xing and Kang, 2013; Loh et al., 2002).

\section{Effect of near-fault earthquake on structures}

Near fault earthquake usually carries one or more pulses in its velocity time histories as shown in fig.6 (Chopra and Chintanapakdee, 2001; Soltangharaei et al., 2016) which grasps the larger elastic spectral acceleration in the short to lengthier time periods striking severe damages to the structures and larger time history response to the bridge structures. Due to the larger spectral 
acceleration values, the structures which experiencing near fault motions cause large impact in secondary and global seismic demand capacity parameters also decreasing range in bending strength and ductility of the structures (Soltangharaei et al., 2016). The seismic design concept of DPH, TPH and EPH applied with tall buildings was investigated with the velocity pulse like ground motions in Fig.7 shows that the models required larger demand in moment envelopes, plastic hinge, curvature ductility, roof drift and displacement as compared with the FF ground motions (Beiraghi et al., 2016).
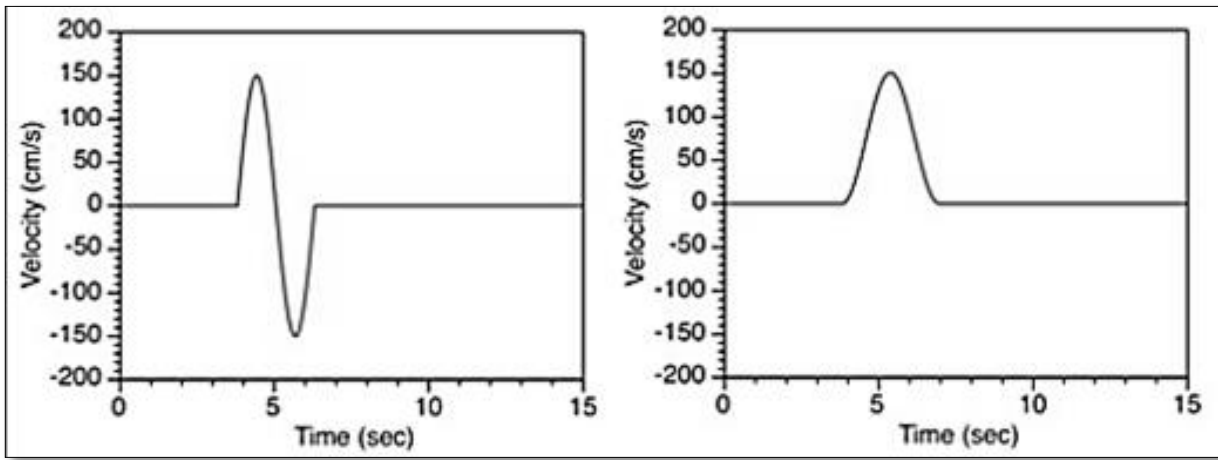

(a)
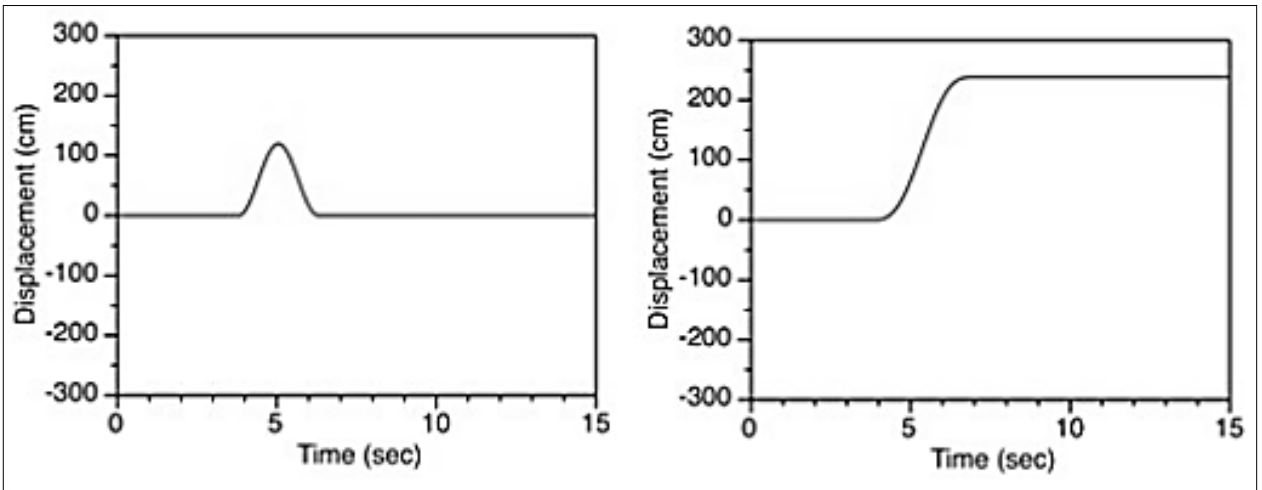

(b)

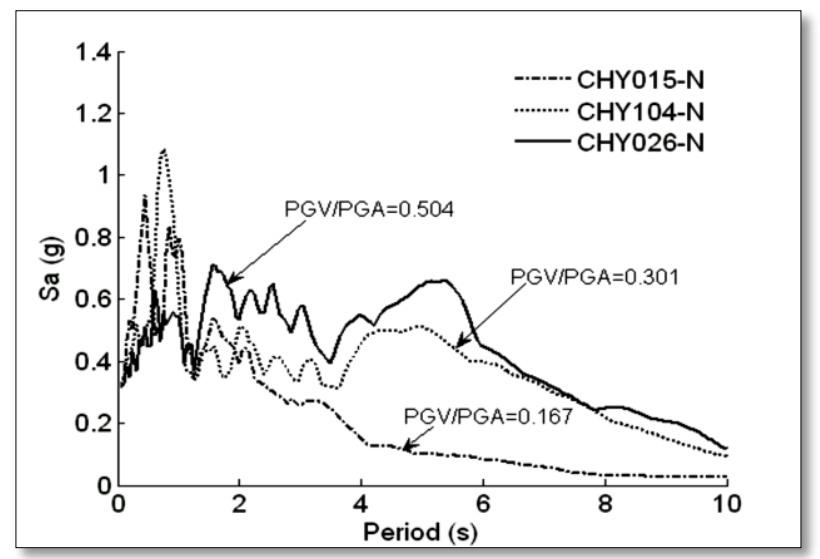

(c)

Fig. 7. (a) Velocity \& (b) Displacement time histories of Directivity and Fling pulse (c) Ground acceleration response spectrum with respect to the ratio of the PGA/PGV

The investigation of the response of elastic and inelastic SDF systems were carried out with the fault-normal component of the set of 15 selected near fault record imposes much larger 
deformation and strength demands compared to the fault-parallel component (Chopra and Chintanapakdee, 2001). Then the investigation further continued in the upcoming days with the Large Crossing Transmission Tower-line System (LCTL) results shows that the seismic response higher scatter than the far field ground motions, when the system correlated with the increasing pulse period of near-fault ground motions. Where the displacement envelope of LCTL are more complex than those of LCTL to fling-step ground motions (Wu et al., 2014). In Multi story steel structures, the study of the effects of forward directivity motions influencing the shape of the maximum story ductility demand and the location of critical story by pulse periods and amplitude of the forward directivity pulse (Sehhati et al., 2011).

\subsection{Effect of near-fault earthquake on bridge structures}

As we know that the near fault ground motions are very intense to the various structures from the previous research studies (Chopra and Chintanapakdee, 2001; Beiraghi et al., 2016; Soltangharaei et al., 2016; Wu et al., 2014 ; Sehhati et al., 2011) as well as those, earthquakes can produce high intensity ground motions which can produce extensive damages to the bridge structures which are playing a vital role in connecting a highway system with major cities. To retain the bridge, structures remain working and undamaged after the earthquakes take place to maintain the serviceability for smooth running of people's daily life. Many researchers took the initiative to study the structural response of bridge structures after the substantial damages created by the near field ground motions in Northridge 1994, Kobe 1995, and Chi Chi earthquakes. Those ground motions were created an unusual structural response over the bridge structures than the conventional far field ground motions. In 2011, a geometrically nonlinear analysis of suspension bridges showed that the near fault ground motion is intensely effective on the displacement and internal forces in the bridges but also the maximum displacement and internal forces not occurs at the near fault peak acceleration value (Adanur et al., 2012). The three span simply supported bridge which is investigated with the near faultnormal and fault-horizontal components and the magnitude higher than the $M=6.0$, the results show that the key forces between the bridge piers and bridge decks are reduced, retains the piers stiffened when the time period $\mathrm{T}_{1}$ in between the 0.1 and $0.3 \mathrm{~s}$ When the magnification factor became larger with the small values of $\mathrm{T}_{1}$ the torsional stiffness of the adjacent deck increased with the results of increased drifts of the piers about $25 \%$ to $40 \%$ by the wave passage effects. It also showed that the maximum deformations of the deck girder increasing the larger demands on the piers without doubt (Jalali et al., 2012).

The response of the Karnali cable stayed bridges were studied with the near fault earthquakes in the two phases 'regular' and 'inverse' which is the structure subjected to the horizontal accelerations and the second stage combined horizontal and vertical components, the effect of FDGM shows that the base moment and base shear of the tower amplifies when the pulse period coincides with the natural period of the structure and also the tower base resisting the 'regular' ground motion within the elastic range but there is comprehensive damage with complex level of residual displacement when the 'inverse' ground motion applied to the structure (Shrestha and Tuladhar, 2012). In 2014, Next Generation Attenuation (NGA) project conducted the study based on the High Speed Railway system which is subjected to near-fault ground motions and compared the results with far fault ground motions where the response of the girder and pier top tends to increase the displacements demands as shown in Fig.8 with the reversed cycles of loading (Ling-kun et al., 2014). Due to the larger values of the acceleration ratio $\partial_{\mathrm{PGA}}$ in nearfault ground motions tends to increase the higher upright deflections over the mid-span of the girder, which can alter the axial loads in pier (Jalali et al., 2012; Ling-kun et al., 2014; Chen et al., 2014). The response of the Sutong Cable stayed bridge with the forward directivity with fling step ground motions and the artificial pulses near-fault pulse-type ground motions were studied by the researchers and the results shows that the fling step ground motions which have low 
PGV/PGA, enforce larger deformation and internal forces over the structure than the forward directivity motions (fig.5) (Li et al., 2017; Hajali et al., 2018).

In 2016, there was also an investigation initiated over the curved continuous railway bridges with frequent earthquakes and the assumptions made by earthquake strikes with the first train entering the bridge at different time instants as well as various sets of earthquake records examined.
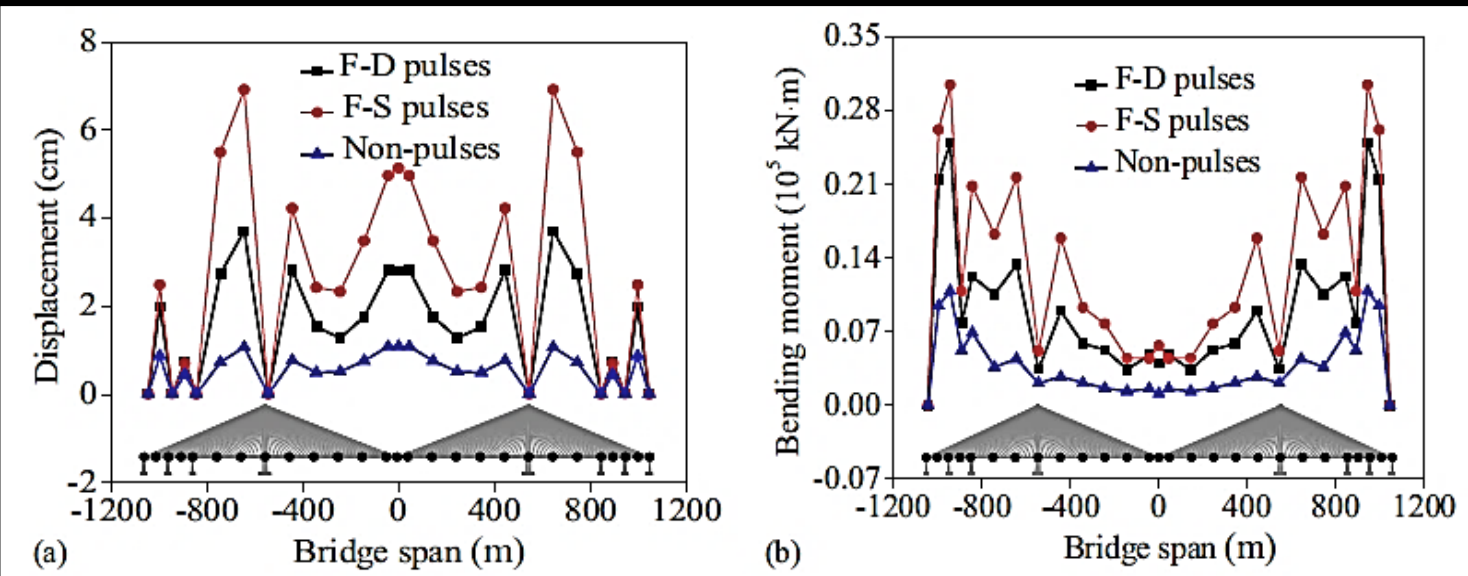

Fig. 8. Average peak response of the girder: (a) Vertical displacement; (b) Bending moment (Note: F-D pulses denote the forward-directivity records, F-S pulses denote the fling-step records (Shuai Li, et al 2016)[25]

In the first level of investigations shows that the position of running vehicle over the earthquake excitation is unpredictable so the train vehicles examined with different positions on the deck when the earthquake commences and proved that the response of the first vehicles higher when they running over the bridges due to the seismic response of the bridge (fig.9) (Zeng and Dimitrakopoulos, 2016).

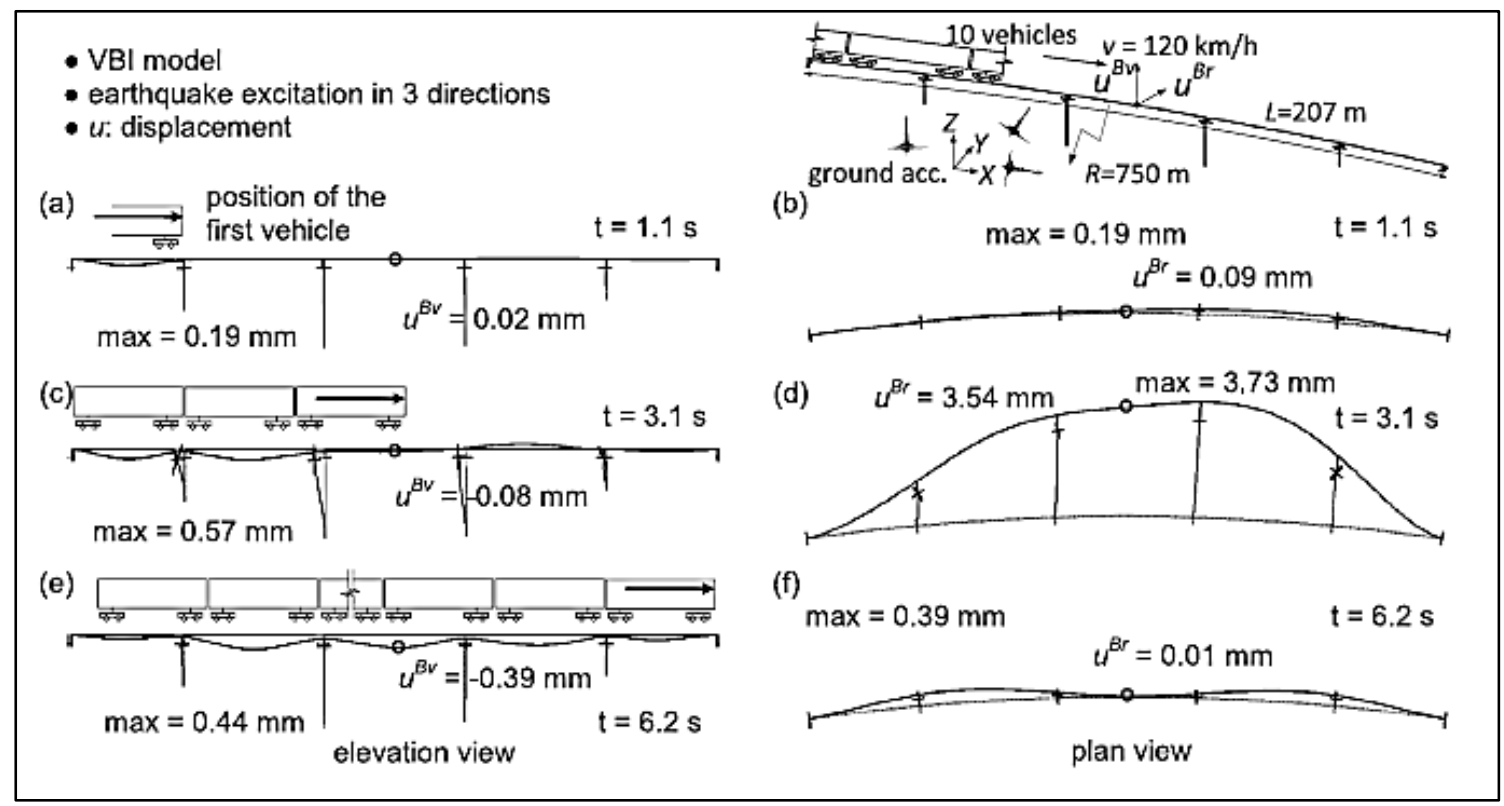

Fig. 9. The deformation shape of the bridge induced by moving vehicles with simultaneous earthquake excitations (Zeng, et al 2016)

Due to the usage of continuous girder increases over HSR bridges to overcome the undulating terrain and satisfy the safety running of vehicles, the experimental shake table test investigated on the bridge structure to study the seismic response under the peak ground acceleration of 0.38 
g earthquake motions. The shake table results show that the increase in peak ground acceleration (PGA from $0.45 \mathrm{~g}$ to $1.14 \mathrm{~g}$ ) which leads to decrease the frequency of piers which also reduces the overall stiffness of the pier subjected to the bidirectional earthquake excitation (Jiang et al., 2019).

Recently, the investigation was carried out to analyze the seismic behavior of the long-span concrete filled tubular arch bridge with fling step motion which can cause more damage to the long-span bridges. The Effect of fling-step motion on seismic performance evaluated by some observations, two serious regions of the CFST arch where the arch foot is subjected to the buckling load tube tearing due to the initial compressive state of the arch rib under the gravity action and the strain index investigation has shown that the microscopic strain distribution significantly different than the macroscopic dynamic indices (Xin et al., 2019). Wei et al. (2018), investigated the damager features of different main components in HSR Simply supported HSR Bridge under near fault earthquake, the results proved that the background excitations with high frequency motions produced nearly $90 \%$ of the pier displacement response, $80 \%$ of the sliding layer response, and $85 \%$ of the shear alveolar response and concluded that the sliding layer and the shear alveolar are the weakest components which leads to failure of the track system (Guo et al., 2020).

\section{Effects of moving loads in railway bridges}

\subsection{Moving loads}

The development of high-speed train system started in several countries like Japan, Germany, Korea, and China with different level of speed improvements as per their requirements. When the speed increases more than the $250 \mathrm{~km} / \mathrm{Hr}$, there is a massive rise in research contribution to improve the safety and comfort running of train vehicle and effective track arrangement. Moving speed of HSR differed from different countries like China (CHR3 - 350Km/hr), Japan and France (TGV \& Shinkansen - 250km/hr), Germany (ICE- $280 \mathrm{~km} / \mathrm{hr}$ ) and Korea (KTX-300km/hr). While evaluating the dynamic behavior of bridge structures which is subjected to high speed train moving load is one of the most important factors to be considered for the structural well-being concerns. Therefore many researchers took the initiative to study the dynamic behavior of vehicle - track interaction when the operating speeds of the vehicle are increasing to $350 \mathrm{~km} / \mathrm{hr}$ with 2D \& 3D models for predicting the exact outcomes. Various studies point out that the moving load causing the vibrations to the bridges which can affect the running stability and also the safety of the moving vehicles, it is mandatory to consider the moving load as a major factor to perform the dynamic analysis of the railway bridges (Mittal et al., 2016). When the high speed train above $160 \mathrm{~km} / \mathrm{hr}$ passing through the small or medium span railway bridges which induce resonance from the parameters of the bridge(natural frequencies of bridge) and train (Axles distances of the train, train speed) replicates increase in dynamic response with increase in deflection amplitude of the superstructure (Goicolea et al., 2010).

\subsection{Effect of moving loads}

The dynamic effect study conducted with the simplified 2D model as shown in Fig.10 of acceptable finite element track and a vehicle model, which shows that the vehicle interaction force which is initiated by the primary suspension in the bogie between the wheel and the rail were very sensitive to the irregularity of the track and vehicle passing speeds.[30] And to overcome the complexity of 3D models, where the 2D planar models (Orthotropic plate FE model) were used to study the dynamic behavior and the serviceability limit of the infrastructure experienced by the train vehicle traffic shows that the structure undergoing most alarming vertical acceleration when the train hits above $200 \mathrm{~km} / \mathrm{hr}$ to $270 \mathrm{~km} / \mathrm{hr}$ operational speed which leads to experience the excessive vibration with growing fatigue problems and facing inadmissible vertical acceleration initiated by the resonance of first longitudinal bending 
mode of plane beam model. Some of the researchers used mathematical simulation to simulate the dynamic performance of vehicle-bridge interaction with moving vehicle loads. For example, the mathematical model superposition analysis approach presented with small and medium span simply supported railway bridges subjected to a series of moving vehicles with identical loads (IC coaches- $160 \mathrm{~km} / \mathrm{hr}$ ) which shows that the higher number of moving loads creates free vibration results in the resonance vibration having adverse effects on the degradation of the super structure. And the observed that the resonance amplitude enhances the dynamic deflection in short to medium spans influenced by the ratio of length to velocity, the driving frequency of the vehicle in structure and the natural frequency of the bridges and the resonance amplitude can be decreased with the increasing damping stiffness value.[Milan MORAVČÍK1, 2017 \#66]

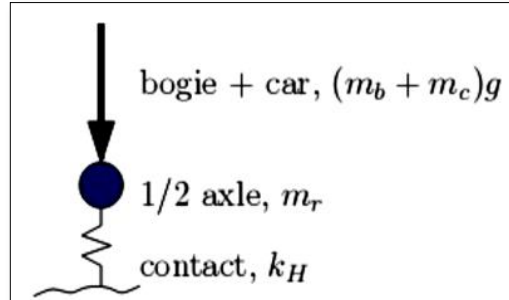

$1 / 2$ axle, 1 gdl

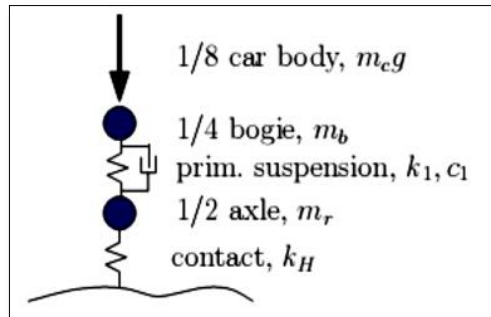

$1 / 4$ bogie: 2 gdl

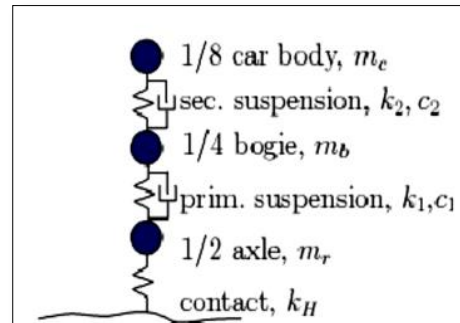

1/8 vehicle: 3 gdl

Fig. 10. Simple 2D models of multi body vehicle models with many degrees of freedom a) Single degree of freedom b) Two degree of freedom c) Two degree of freedom

Some researchers also compared the results with experimental and analytical to study the impact effects like Impact factor (IM) of the moving train on the bridge to ensure the reliability of the bridge and safety run of train, the study came up with the results where the IM strongly depends on the track irregularities but also its increase with the speed of the train and decreases with the increase of train weight. And the observation cleared that the track irregularities are also increase the IM which can lead to track surface degradation, and the train-bridge interaction will be more intense for long-term operation of the bridge structure for safety running of train vehicle. [Gou, 2018 \#68] And the same author studied the dynamic behavior of Tied arch railway bridge under the moving train load, observed that the increase in train speed increases the vertical and transverse accelerations and also increases the derailment coefficient under double line loading is less than that of single line loading.[Hongye Gou0, 2019 \#69] Recently the study carried out with the double simply supported beam system subjected to the moving loads using the combination of finite sin-fourier transform and numerical Laplace transform based on Durbin transform, an analytical calculation method was developed for the spatial displacement time-domain response of a multiple simply supported beam system and also compared with the finite element analysis using ANSYS software results and it shows that the double beam system has multiple points of resonance and cancellation which may cause unexpected situations in future and also the variation in mass and flexural stiffness parameters of first simply supported beam initiates problems for the dynamic responses for second simply supported beam in the double simply supported rail-bridge system.

\section{Conclusions}

By studying the literatures based on the near fault ground motions and moving load and their effects on the dynamic behavior of high-speed railway bridges are a complex behavior to be considered in the upcoming research studies and working on updating the design codal provisions regarding the response reduction factor parameters which can reduce the dynamic response of the bridges. And the significant conclusions can be drawn as follows as 
- Many of the researchers talked about the effects of far fault earthquake motions, but not much paper dealing with the near-fault motion creates impulsive velocity effect and the hanging wall effect which can induce $46-60 \%$ of higher PGA values indicates the ground acceleration response spectrum area width will be further wider which is always interrelated to the structural response of the HSR Bridges and as well as the safety run of trains.

- The effect of near-fault motions over the bridges, where increasing displacement and internal forces, increased drifts of the piers about $25 \%$ to $40 \%$ by the wave -passage effects, concluded that the sliding layer and the shear alveolar are the weakest components which leads to failure of the track system.

- To overcome the complexity of 3D models of the Train - bridge interaction, 2D models were sufficient than the 3D models to get the exact outcomes of the dynamic behavior of vehicle - track interaction when the vehicle running speed is over $200-350 \mathrm{~km} / \mathrm{hr}$.

- The effect of moving loads over the bridges where the resonance caused by the various parameters of train (Axles distances of the train, train speed and weight of the train) and the irregularity of the track causes increase in deflection amplitude, growing fatigue problems, inadmissible vertical and horizontal acceleration, derailment coefficient

- Its observed that China has the HSR bridge ratio of $1.3-32.2 \%$, which clearly shows that the high speed train operates over the bridges is most of the time when the earthquake occurs, which may cause to experience excessive vibrations with the resonance induced by the moving vehicles loads when the operating speed hits up to $200-350 \mathrm{Km} / \mathrm{hr}$. But there is not at all sufficient research found that considering effects of both moving load (From vehicle to the structure leads to the ground) and earthquake loads (From ground to structure to the vehicle) to study the dynamic behavior of the High speed train bridge structures

\section{Declarations}

\section{Abbreviations}

HSR: High Speed Train; PGA: Peak Ground Acceleration; NF: Near-Fault; F.F: Far Fault; PGV: Peak Ground Velocity; SDOF - Single Degree Of Freedom; DPH- Dual Plastic Hinge; TPH- TriplePlastic Hinge; EPH: Elasto Plastic Hinge; LCTL: Large Crossing Transmission Tower-line System; FDGM-Forward Directivity Ground Motions; CFST: Cold Formed Steel Tubular; IM: Impact Measure.

\section{Acknowledgements}

The authors would like to acknowledge all the mentioned reference for sharing their database on High Speed Train bridges, Near-fault earthquakes.

\section{Authors' contributions}

Both author contributed equally to the formulation and drafting of this paper. The authors read and approved the final manuscript.

\section{Funding}

No funding was received during this research.

\section{Availability of data and materials}

The data can be requested from the authors.

\section{Competing interests}

The authors declare that they have no competing interests. 


\section{References}

Adanur, S., Altunișik, A. C., Bayraktar, A., \& Akköse, M. (2012). Comparison of near-fault and far-fault ground motion effects on geometrically nonlinear earthquake behavior of suspension bridges. Natural hazards, 64(1), 593-614.

Akkar, S., Yazgan, U., \& Gülkan, P. (2005). Drift estimates in frame buildings subjected to near-fault ground motions. Journal of Structural Engineering, 131(7), 1014-1024.

AREMA (2018). American Railway Engineering And Maintanence of way Associaction. AREMA Manual for Railway Engineering.

Beiraghi, H., Kheyroddin, A., \& Kafi, M. A. (2016). Forward directivity near-fault and far-fault ground motion effects on the behavior of reinforced concrete wall tall buildings with one and more plastic hinges. The Structural Design of Tall and Special Buildings, 25(11), 519-539.

Chen, L. K., Zhang, N., Jiang, L. Z., Zeng, Z. P., Chen, G. W., \& Guo, W. (2014). Near-fault directivity pulse-like ground motion effect on high-speed railway bridge. Journal of Central South University, 21(6), 24252436.

Chopra, A. K., \& Chintanapakdee, C. (2001). Comparing response of SDF systems to near-fault and far-fault earthquake motions in the context of spectral regions. Earthquake engineering \& structural dynamics, 30(12), 1769-1789.

Davoodi, M., Sadjadi, M., Goljahani, P., \& Kamalian, M. (2012). Effects of near-field and far-field earthquakes on seismic response of sdof system considering soil structure interaction. In 15th World Conference on Earthquake Engineering. Lisbon, Portugal.

Goicolea, J. M., Nguyen, K., Galbadón, F., Bermejo, M., Topping, B. H. V., Adam, J. M., ... \& Romero, M. L. (2010). Dynamic Analysis of High Speed Railway Traffic Loads on Ballast and Slab Tracks. In Proceedings of the Tenth International Conference on Engineering Computational Technology. CivilComp Press.

Guo, W., Gao, X., Hu, P., Hu, Y., Zhai, Z., Bu, D., \& Jiang, L. (2020). Seismic damage features of high-speed railway simply supported bridge-track system under near-fault earthquake. Advances in Structural Engineering, 23(8), 1573-1586.

Hajali, M., Jalali, A., \& Maleki, A. (2018). Effects of near fault and far fault ground motions on nonlinear dynamic response and seismic improvement of bridges. Civil Engineering Journal, 4(6), 1456-1466.

He, X., Wu, T., Zou, Y., Chen, Y. F., Guo, H., \& Yu, Z. (2017). Recent developments of high-speed railway bridges in China. Structure and Infrastructure Engineering, 13(12), 1584-1595.

Jalali, R. S., Jokandan, M. B., \& Trifunac, M. D. (2012). Earthquake response of a three-span, simply supported bridge to near-field pulse and permanent-displacement step. Soil Dynamics and Earthquake Engineering, 43, 380-397.

Jamnani, H. H., Karbassi, A., \& Lestuzzi, P. (2013). Fling-step effect on the seismic behaviour of high-rise RC buildings during the Christchurch earthquake. In 2013 NZSEE Conference.

Jiang, L., Kang, X., Li, C., \& Shao, G. (2019). Earthquake response of continuous girder bridge for high-speed railway: A shaking table test study. Engineering Structures, 180, 249-263.

Kim, Y. S., \& Sanderson, D. J. (2008). Earthquake and fault propagation, displacement and damage zones. Structural geology: new research, 1, 99-117.

Li, S., Zhang, F., Wang, J. Q., Alam, M. S., \& Zhang, J. (2017). Effects of near-fault motions and artificial pulsetype ground motions on super-span cable-stayed bridge systems. Journal of Bridge Engineering, 22(3), 04016128

Ling-kun, C., Li-zhong, J., Wei, G., Wen-shuo, L., Zhi-ping, Z., \& Ge-wei, C. (2014). The seismic response of high-speed railway bridges subjected to near-fault forward directivity ground motions using a vehicle-track-bridge element. Shock and Vibration, 2014. Volume12, Article ID 985602. 
Loh, C. H., Wan, S., \& Liao, W. I. (2002). Effects of hysteretic model on seismic demands: consideration of near-fault ground motions. The Structural Design of Tall Buildings, 11(3), 155-169.

Mittal, R. K., Sai, V. K., \& Maiti, P. R. (2016). Effect of Mass of Moving Load on Dynamic Response of a Simply Supported Railway Bridge. i-Manager's Journal on Structural Engineering, 5(4), 23.

Sehhati, R., Rodriguez-Marek, A., ElGawady, M., \& Cofer, W. F. (2011). Effects of near-fault ground motions and equivalent pulses on multi-story structures. Engineering Structures, 33(3), 767-779.

Shrestha, B., \& Tuladhar, R. (2012). The response of Karnali Bridge, Nepal to near-fault earthquakes. In Proceedings of the Institution of Civil Engineers-Bridge Engineering, Thomas Telford Ltd., 165 (4), 223-232.

Soltangharaei, V., Razi, M., \& Gerami, M. (2016). Comparative evaluation of behavior factor of SMRF structures for near and far fault ground motions. Periodica Polytechnica Civil Engineering, 60(1), 7582.

Tao, X. X., \& Wang, G. X. (2003). Rupture directivity and hanging wall effect in near field strong ground motion simulation. Acta Seismologica Sinica, 16(2), 205-212.

Wei, B., Yang, T., Jiang, L., \& He, X. (2018). Effects of uncertain characteristic periods of ground motions on seismic vulnerabilities of a continuous track-bridge system of high-speed railway. Bulletin of earthquake engineering, 16(9), 3739-3769.

William, G., \& Byers, P. E. (2004). Railroad lifeline damage in earthquakes. In 13 World of Conference on Earthquake Engineering.

Wu, G., Zhai, C., Li, S., \& Xie, L. (2014). Effects of near-fault ground motions and equivalent pulses on Large Crossing Transmission Tower-line System. Engineering structures, 77, 161-169.

Wu, S. L., Charatpangoon, B., Kiyono, J., Maeda, Y., Nakatani, T., \& Li, S. Y. (2016). synthesis of near-Fault ground Motion Using a hybrid Method of stochastic and Theoretical green's Functions. Frontiers in Built Environment, 2, 24.

Xia, H., Han, Y., Zhang, N., \& Guo, W. (2006). Dynamic analysis of train-bridge system subjected to nonuniform seismic excitations. Earthquake Engineering \& Structural Dynamics, 35(12), 1563-1579.

Xiao, D.Y., (2015). China - a Country of Many Earthquakes. Computer Network Information Center of Chinese Academy of Sciences.

Xin, L., Li, X., Zhang, Z., \& Zhao, L. (2019). Seismic behavior of long-span concrete-filled steel tubular arch bridge subjected to near-fault fling-step motions. Engineering Structures, 180, 148-159.

Xing, F., \& Kang, R. (2013). Response Spectrum Characteristics of Near-Fault Ground Motions and Influence to CFST Arch Bridge. In Advanced Materials Research. Trans Tech Publications Ltd., 671, 1367-1371.

Zeng, Q., \& Dimitrakopoulos, E. G. (2016). Seismic response analysis of an interacting curved bridge-train system under frequent earthquakes. Earthquake Engineering \& Structural Dynamics, 45(7), 11291148. 